\title{
BORJESON-FORSSMAN-LEHMANN SYNDROME IN A GIRL
}

\author{
Kiyosato Matsuo, Ichiro Murano, and Tadashi KaJu \\ Department of Pediatrics, Yamaguchi University School of Medicine, \\ Ube, Yamaguchi 755, Japan
}

\begin{abstract}
Summary A 3 11/12-year-old Japanese girl was found to exhibit typical clinical features of the Borjeson-Forssman-Lehmann syndrome, including severe mental retardation, epileptic seizures controllable by anticonvulsants, obesity, microcephaly, a coarse facies with prominent supraorbital ridges and deep-set eyes, bilateral internal strabismus, large ears, small hands with tapering hyperextensible fingers and metaphyseal widening of the long bones. She showed hyperresponsive patterns of serum luteinizing and follicule-stimulating hormones upon LH-RH loading. Her karyotype was normal. The parents were mentally and phenotypically normal. The inheritance of the disease was compatible with $\mathrm{X}$-linked recessive in six kindreds in the literature. Skewed $\mathrm{X}$ inactivation was considered the most likely mechanism for the occurrence of the disease in a girl.
\end{abstract}

\section{INTRODUCTION}

Borjeson-Forssman-Lehmann syndrome was first described by Borjeson, Forssman and Lehmann $(1961,1962)$ in three related males with severe mental deficiency, epilepsy, hypogonadism, obesity and dysmorphic facies. All affected males in the kindred were related through common female relatives. Subsequently, nine more male patients in five families were reported (Baar and Galindo., 1965; Webers et al., 1978; Veall et al., 1979; Hutchinson et al., 1981; Robinson et al., 1983). Female heterozygotes in the family reported by Borjeson et al. and in the other five families ranged from those without any observable abnormal features to those with moderate mental deficiency and some of the abnormalities of growth and craniofacial, ocular, and skeletal features characteristic of the syndrome. Thus, the disease is likely to be inherited as X-linked recessive.

We report here a 3-year-old girl with typical clinical features of the syndrome including severe mental retardation.

Received March 19, 1984 


\section{CASE REPORT}

The $311 / 12$-year-old girl was born to unrelated and healthy parents through vaccum extraction after a 40 weeks of pregnancy with a weight of $3,210 \mathrm{~g}$ and a height of $48.3 \mathrm{~cm}$. Her mother was 25 -year-old and the father 28 -year-old. The pregnancy was complicated by threatened abortion in the second trimester. The father, a fisherman, measured $168 \mathrm{~cm}(+0.3 \mathrm{SD})$, and the mother $158 \mathrm{~cm}(+0.8$ $\mathrm{SD})$. The parents were of average intelligence. The younger sister, born 4 years later, was apparently normal when examined at age 3 months. There were no mentally retarded close relatives on either side (Fig. 1). The patient's developmental milestones were delayed: she achieved head control at 4 months, smiled at 6 months, sat at 7 months and walked at 18 months. Neither hypotonia nor feeding difficulty was noted in infancy. Since age 2 years she has had several grand mal seizures controllable by anticonvulsants. Electroencephalography at 2 years revealed no abnormalities.

When seen at $311 / 12$ years, her height was $96.5 \mathrm{~cm}(-0.4 \mathrm{SD})$, weight 20.4 $\mathrm{kg}(+4.0 \mathrm{SD})$ and head circumference $48.0 \mathrm{~cm}(-0.6 \mathrm{SD})$. She had a coarse facies with a narrow forehead, prominent supraorbital ridges, deep-set eyes with bilateral internal strabismus, a depressed nasal root, soft puffy cheeks, and large ears (Fig. 2). The right ear measured $60 \mathrm{~mm}(+3 \mathrm{SD})$ and the left ear was $59 \mathrm{~mm}(+2.9$ SD). The skin was soft and doughy. Her hands were small, soft and fleshy with tapering fingers. The wrists and metacarpophalangeal joints were heperextensible. When pressed backward, fingers were held parallel to the dorsum of the forearm. Her external genitalia were those of a prepubertal female. She was restless, spoke no meaningful words, but was friendly. She was not toilet trained. Her developmental quotient was estimated at 25, using the Tsumori and Inage Scale (1981) of

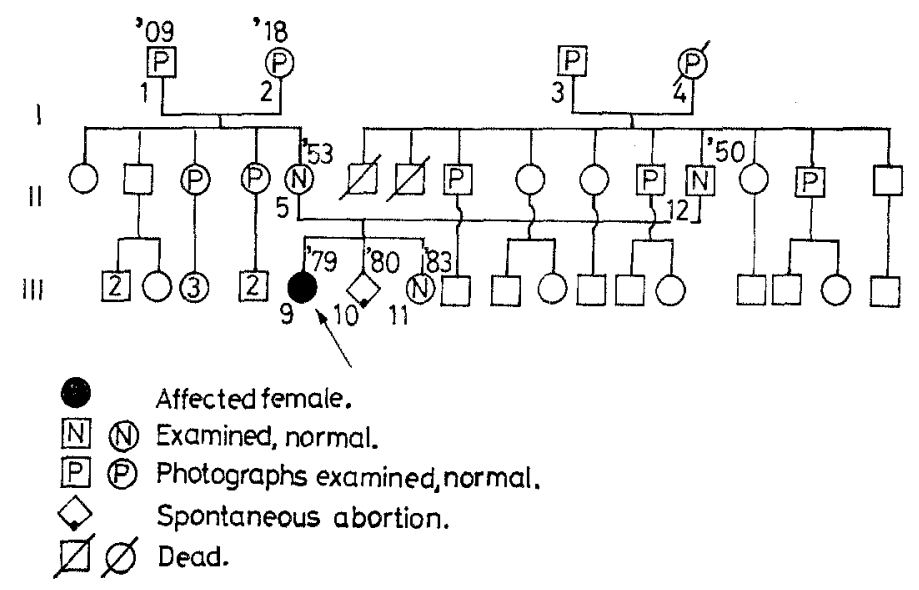

Fig. 1. The pedigree. 

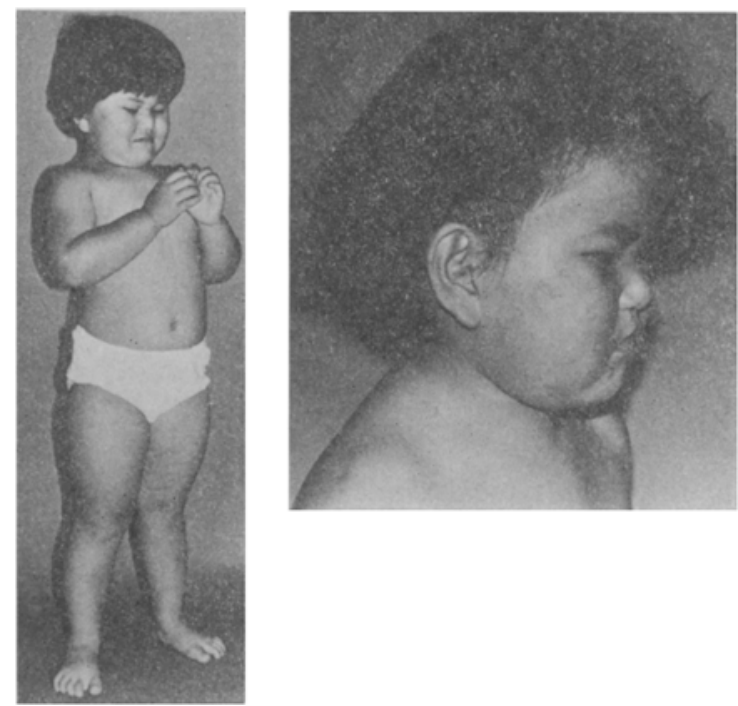

Fig. 2. The patient at age $311 / 12$ years. Trunchal obesity (left), a coarse facies with a narrow forehead, prominent supraorbital ridges, deep-set eyes, a depressed nasal root, puffy cheeks, and large ears (right).

Table 1. LH-RH loading test.

\begin{tabular}{ccc}
\hline $\begin{array}{c}\text { Time after } \\
\text { loading } \\
\text { (min) }\end{array}$ & \multicolumn{2}{c}{ Serum level of } \\
\cline { 2 - 3 } & LH (mIU/ml) & FSH $(\mathrm{mIU} / \mathrm{ml})$ \\
\hline 0 & $5(4-10)$ & $6(2-10)$ \\
60 & $32(16-27)$ & $43(11-33)$ \\
90 & $31(16-24)$ & $52(14-26)$ \\
120 & $32(9-20)$ & $55(17-24)$ \\
& $27(8-16)$ & $54(17-20)$ \\
\hline
\end{tabular}

LH-RH injection ( $100 \mu \mathrm{g} / \mathrm{sq} . \mathrm{m}$. intravenously). In parentheses, range of age-matched female controls.

developmental maturity. Fundscopic examination and electrocardiography did not reveal any abnormal findings.

Normal laboratory tests included; serum and urinary amino acids, oral glucose tolerance test, serum $\mathrm{T}_{3}, \mathrm{~T}_{4}$ and $\mathrm{TSH}$, serum estradiol, urinary 17-ketosteroid and mucopolysaccharide excretion. The serum ACTH response upon metyrapone stimulation was normal. The LH-RH test revealed hyperresponsive patterns of serum luteinizing hormone and follicle-stimulating hormone (Table 1). Chromosomal analyses were performed with cultured peripheral blood lymphocytes and skin fibroblasts. A total of 34 lymphocyte and 21 fibroblast metaphases were counted, of which 50 metaphases $(91 \%)$ had 46 chromosomes while 5 showed a random chro- 
mosome loss. Analysis of 3 G-banded lymphocyte and 2 Q-banded fibroblas. metaphases revealed a 46,XX karyotype. High resolution banding analysis (Dutrillaux and Viegas-Pequignot, 1981) of the $X$ chromosomes with about 550 bands per haploid revealed no abnormalities.

Intravenous pyelography and brain CT scan revealed no abnormalities. The carpal bone age was $42 / 12$ years according to the Greulich and Pyle's Atlas (1959). The long bones were undermineralized with thin cortices and showed metaphyseal widening.

\section{DISCUSSION}

Our patient, a girl, had typical clinical features of the Borjeson-ForssmanLehmann syndrome, including severe mental retardation, epileptic seizures controllable by anticonvulsants, less than average height, moderate obesity, a coarse facies with a narrow forehead, prominent supraorbital ridges and deep-set eyes with

Table 2. Comparison of clinical findings in females with BorjesonForssman-Lehmann syndrome patterns.

\begin{tabular}{lcc}
\hline \multicolumn{1}{c}{ Clinical findings } & Patient & $\begin{array}{c}\text { Previously reported } \\
\text { symptomatic } \\
\text { females a }\end{array}$ \\
\hline Growth and function & - & $4 / 8$ \\
Postnatal growth deficiency & + & $3 / 5$ \\
Obesity & + & $7 / 8$ \\
Mental deficiency & + & $3 / 4$ \\
Hypotonia & + & $3 / 5$ \\
Craniofacial & + & $5 / 8$ \\
Microcephaly & + & $4 / 8$ \\
Coarse facial appearance & + & $5 / 8$ \\
Prominent supraorbital ridge with deep-set eyes & - & $1 / 8$ \\
Large ears & - & $1 / 5$ \\
Eyes & - & $3 / 5$ \\
Ptosis & & $3 / 8$ \\
Nystagmus & & \\
Poor vision with retinal, optical nerve, & & \\
lenticular abnormalities & $?$ & $3 / 5$ \\
Genitalia & & \\
Delayed secondary sexual characteristics & + & \\
Skeletal & + & \\
Small hands with tapering hyperextensible fingers & Bilateral internal \\
Variable radiographic abnormalities & strabismus; Seizures \\
Other findings & \\
&
\end{tabular}

a Borjeson et al. (1963); Hutchinson et al. (1981); Robinson et al. (1983). 
bilateral internal strabismus, large but normally formed ears, small hands with tapering fingers (Table 2). Hyperresponsive patterns of her serum luteinizing and follicle-stimulating hormones upon LH-RH loading also supported the diagnosis.

Several explanations are conceivable for the occurrence of a female with an $\mathrm{X}$-linked recessive disease. They include a 45, $\mathrm{X}$ or mosaic 45 , $\mathrm{X}$ karyotype, deletion of the critical segment of an $\mathrm{X}$ chromosome, skewed $\mathrm{X}$ chromosome inactivation, homozygosity for the mutant gene, and a clinically identical but genetically different disease possibly inherited in an autosomal recessive fashion. The presence of a $45, \mathrm{X}$ cell line to the extent as to affect the phenotype is unlikely in our patient in view of the result of our cytogenetic analysis. Deletion of an $\mathrm{X}$ chromosome is also unlikely, although a minor deletion, beyound the limits of resolution of existing methods, cannot be ruled out. Homozygosity for the mutation is unlikely in the absence of similarly affected individuals among close relatives. The existence of a disease, clinically identical with, but genetically different from, the Borjeson-Forssman-Lehmann syndrome is also unlikely. At least six kindreds with the syndrome have been reported in the literature (Borjeson et al., 1963; Baar and Galindo, 1965; Weber et al., 1978; Veall et al., 1979; Hutchinson et al., 1981; Robinson et al., 1983). All were compatible with $X$-linked recessive inheritance. Thus, skewed $X$ inactivation is the most likely explanation for the situation, with a high proportion of cells in which the normal $X$ chromosome was inactivated, leaving the mutant $X$ active.

Sporadic occurrence of an $X$-linked disease, as is the case with our pedigree, suggests fresh mutation in either the maternal or the paternal line. The fact that the mother was born when the maternal grandfather was 44 years old, a relatively advanced age, would suggest that the mutation occurred in the maternal grandfather.

\section{REFERENCES}

Baar, H.S. and Galindo, J. 1965. The Borjeson-Forssman-Lehmann syndrome. J. Ment. Defic. Res. 9: 125-130.

Borjeson, M., Forssman, H., and Lehmann, O. 1961. Combination of idiocy, epilepsy, hypogonadism, dwarfism, hypometabolism, and morphologic peculiarities inherited as an X-linked recessive syndrome. Proc. 2nd Intl. Congr, on Mental Retardation, Part I, Basel: Karger Publishers, Vienna, pp. 188-192.

Borjeson, M., Forssman, H., and Lehmann, O. 1962. An X-linked recessively inherited syndrome characterized by grave mental deficiency, epilepsy and endocrine disorder. Acta Med. Scand. 171: $13-21$.

Dutrillaux, B. and Viegas-Pequignot, E. 1981. High resolution R- and G-banding on the same preparation. Hum. Genet. 57: 93-95.

Greulich, W.W. and Pyle, J.S. 1959. Radiographic Atlas of Skeletal Development of Hand and Wrist, 2nd ed., Stanford Univ. Press, Stanford, Calif.

Hutchinson, H. and Hanson, J.W. 1981. Borjeson-Forssman-Lehmann Syndrome. March of Dimes 14th Annual Birth Defects Conferences, San Diego, Calif, June 14-19, 1981.

Robinson, L.K., Jones, K.L., Culler, F., Nyhan, W.L., Sakati, N., and Jones, K.L. 1983. The Borjeson-Forssman-Lehmann syndrome. Am. J. Med. Genet. 15: 457-486. 
Tsumori, M. and Inage, N. 1981. Developmental Screening Test for Infant. Dainippon-Tosho Co., Tokyo (in Japanese).

Veall, R.M., Brett, E.M., Rivinus, T.M., and Stephens, R. 1979. The Borjeson-Forssman-Lehmann syndrome: A new case. J. Ment. Defic. Res. 23: 231-242.

Weber, F.T., Frias, J.L., Julius, R.L., and Felman, A.H. 1978. Primary hypogonadism in the Borjeson-Forssman-Lehmann syndrome. J. Med. Genet. 15: 63-66. 